\title{
Avoiding Conflict Between Communication Policy and Convergence
}

\section{Terry Cutler}

\begin{abstract}
$A$ ustralia stands at the end of one policy era in communications and the beginning of another. Over a decade ago, in 1987, the then Cabinet established a Structural Adjustment Committee which initiated a process of telecommunications and broadcasting review and reform that has taken the last decade to work through. Competition policy has driven the structural adjustment agenda. Now, more than a decade later and on the verge of a new century, it is opportune to draw a line in the shifting sands of industry change and to set an agenda for the next generation challenge of policy reform. This new agenda revolves around convergence and the challenges of structural adjustment within the emerging Information Economy.
\end{abstract}

\section{The Need for a New Framework}

The high water mark of Australia's communications reform program was reached with the Telecommunications Act 1991, the introduction of network competition, and the new Broadcasting Services Act 1992. In parallel there were significant changes to institutional structures, with a proliferation of new regulatory agencies. Almost immediately, however, the elegant structure of the Broadcasting Services Act was spoiled by clumsy additions to cater for Pay Television, which produced a broadcasting piece of competition policy that was immediately captured by the new duopoly telecommunications players. Meanwhile other media players remained locked out of new developments by rigid cross-media rules. Different licensing and ownership rules were maintained for different categories of player.

In 1991, the Internet was a little known academic experimental network. Digital broadcasting was something for the future. Few predicted the speed with which non-voice traffic would overtake voice traffic. Australia Post, separated from its 'Siamese Twin' of Telecom Australia in the 1975 surgical transmutation of the Postmaster General's Department, remained to one side as a separate issue

Terry Cutler is Deputy Chairman of the Australian Information Economy Advisory Council, a member of the International Advisory Panel of Malaysia's Multimedia Supercorridor, and a director of Cinemedia Corporation. From 1996 to 1998 he chaired the Industry Research and Development Board. 
for attention by a new National Competition Council. But quietly Australia Post has since emerged from the sidelines as Australia's most extensive retail and financial network and is now a key player in the provision of electronic commerce platforms.

The industry has undergone enormous change since the last reform agenda of the 1980s. Over the last two years Australia has tried to tack on new legislative and regulatory annexes to deal with online services and the demands of an information economy, but the whole structure is looking decided awkward.

Internationally, advanced countries have been slow to respond to the policy challenges of convergence. This reflects the stickiness of entrenched regimes and arrangements. Nonetheless, the European Union has started to canvass a convergence agenda (Squire, Sanders \& Dempsey LLP, with Analysis Ltd, 1998), and recently the OECD has begun to discuss the challenge of 'next generation regulation' (OECD, 1998). But it is some of the new-world countries, like Japan and Malaysia that have taken the lead in defining radical change. Malaysia, for example, has recently enacted a new Communications and Multimedia Act (Malaysia, 1998) to replace the prior telecommunications and broadcasting regimes and is moving to implement new regulatory structures.

The issue now is whether the maintenance of the status quo in Australia and other OECD countries is sustainable. Has industry change reached the point where policy and regulatory lag is likely to cause market distortions and inefficient national resource allocation? Does the current regime distort investment decisions, including investment in infrastructure? Does the current regime hold back consumer benefit? Have industry bottlenecks been displaced by regulatory bottlenecks, blocking access to service benefits and innovation? Does the current regime undermine our efforts to capture the potential of the Information Economy?

The answer to all these questions is a resounding yes. A full review of the policy and regulatory implications of convergence to establish a reform agenda for early attention is a matter of priority. The starting point should be the recognition that convergence is happening, that it should be allowed to happen, and that convergence policies should serve the interests of users and of economic development. Whether the world outside the United States captures the benefits of convergence will depend largely on responses to the imperatives of industry restructuring and the new global information economy. We can be active participants in change, moulding it to our advantage, or we can be victims of change.

\section{What is Convergence?}

The first step in developing a coherent model of the convergent industry environment of the future is to set up a useful definition of the term 'convergence'. Clearly, a definition of convergence must underpin any 
discussion of its impact and the nature of possible policy responses. Despite the apparent wisdom of this observation, the communications policy debate provides little evidence of any definition that could inform a rigorous analysis of convergence and its effects.

There is no universally accepted definition of convergence. The term has been used variously to describe a process of technological development, the merger and acquisition strategies of corporations, and new types of service. The working definition my colleagues and I have used in a variety of policy studies is as follows:

Convergence is the progressive integration of the value chains of the information and content industries - telecommunications, posts, broadcasting, print, multimedia, and data processing into a set of linked economic markets and a single value chain based on the use of distributed digital technology.

This definition is not compellingly elegant, but it focuses on the crucial aspects of the commercial dynamics at work. These are that:

- convergence relates to a process of market and industry restructuring; and

- convergence involves the emergence of new economic markets based on digitisation and networking.

The important process aspect of convergence reflects the challenge of integrating business systems characterised by strong legacy regimes, each of which now needs to adjust to the new imperatives of digitisation. The impact of digitisation has been amplified by related developments in switching and transmission technology, and in radiocommunications technology, which have provided access to far more wired and wireless bandwidth than was possible over the preceding two decades. Prior to the development of modern digital technology from the 1970s, these information and content industries were commercially distinct in all countries. This segmented industry structure was reinforced by regulation that prevented integrated business strategies by firms (OECD, 1998:4).

Before convergence, there were clear distinctions between the 'transport' industries such as telecommunications and posts, the 'content-based' industries such as broadcasting and print, and the 'data processing' industry which began as an in-house function of major corporations with technical support and supply provided by the computer industry. Often these distinctions reflected technological medium or the types of 'hardware' used by the industry such as paper for print, radiocommunications for broadcasting, wires for telecommunications, and mainframes for the computer industry.

At the time, these categories seemed stable. However, certain applications capabilities had not emerged, such as programmable subscriber management 
systems, intelligent network services, and higher level networking technologies for encryption, authentication, structured data transport and transaction processing. In a convergence environment, these new applications services are responsible for much of the new value generated within the digital value chain.

\section{Convergence and the New Digital Services Value Chain}

Convergence creates new business systems. The generic building blocks of the digital economy, all of which are supported by information technology hardware, software and support services, comprise:

- Content creators;

- Publishers, packagers, and programmers;

- Content services;

- Application services providers;

- Network facility and service providers; and

- User interface facilities and services.

These blocks combine together to form the new digital value chain and is illustrated schematically in the accompanying figure.

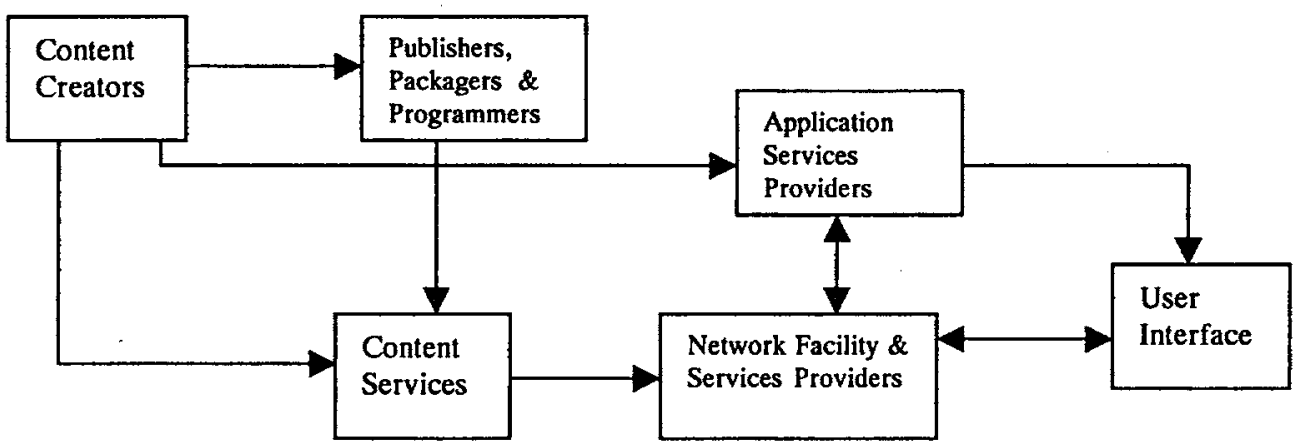

The art of applying this model of a digital services value chain to specific industry situations is in exploring the inter-relationships and dynamics within a period of rapid change. This model of the underlying dynamics of the digital economy serves as a useful road map for the conduct of any policy review because it helps position industry capabilities and development requirements 
within the overall landscape of the information economy. In particular, this analytical approach:

- highlights the interdependent aspects of current sector restructuring;

- focuses attention on the upstream and downstream impacts of different solutions or approaches within sector segments; and

- helps identify gaps in current arrangements that need policy attention.

Applying a road-map model that is totally grounded on the realities of the emerging digital environment ensures that legacy assumptions and traditional approaches are re-examined within a context that can provide a robust framework for setting future directions.

\section{Business Functions in the Digital Value Chain}

There is a range of participants across the digital value chain, all of whom now have a direct interest in the issue of convergence and the policy and regulatory arrangements that will shape their business fate.

\section{Content creators}

Content creators are, for the purposes of the digital value chain, the producers of the raw material for content services. They are the generators of intellectual property and creative works often protected by copyright or other mechanisms. It is taken for granted that this material can be digitised for transport across a digital network. Content creators include journalists and writers, musicians, photographers, film and video makers, software developers, and multimedia developers.

The power of modern digital production and post-production technology means that the product of almost any creative endeavour can be digitised and enhanced. The data can then be represented in a number of modes. Text, for example, can be represented as a printed page, as a web page, or read out by a synthesised voice.

\section{Publishers, packagers and programmers}

The function of publishers, packagers and programmers ('infomediaries') is to apply editorial and programming skills to develop an integrated and meaningful experience for the user from a range of content resources. These resources might include material prepared in the very recent past in response to current events joined to archival material to place current material in context. At the other extreme is the content production of data compilations. 
A key element of this business function is the development of a strong brand loyalty from users, based on past quality and consistency. Since the product changes from day to day or from hour to hour on the Internet, the brand and the reputation it represents is needed to 'present the credentials' of the service again and again in the marketplace. The brand - the 'masthead' in the parlance of the print media, Channel or Station identity in broadcasting, and imprint in books publishing - is a principal asset of this business. In a convergent environment, brands are characterised by an integrated approach to the management of intellectual property and a presence across more than one form of media that protects the brand from the risk of unexpected technological change.

\section{Network providers}

A 'network' means more than the physical components of wires, optical fibre, antennas and switches. The network is best thought of as a 'system' or 'platform' that supports a potentially unlimited number of different applications. This platform consists of the physical infrastructure together $v$ ith the softv are operating systems that provide network functionality.

The logical function of a network platform is simply to transport digital data from an originating point to a designated destination. It will not matter whether the link is wired or wireless, or whether it is used for telecommunications, broadcasting or distributed computing. All communications and computer applications services will run over the same basic platform. 'Network providers' will be those who are in the business of providing these platforms and managing connectivity.

It follows that mobile, wireless and wired facilities providers will be operating in the same market. From a service perspective, it is becoming difficult to distinguish between these technologies, which have become substitutable. From a policy perspective, it will become increasingly dysfunctional to regulate by technology type.

\section{Applications service providers}

In a digital age, all communications services are applications services. These services are embodied on the network as applications software that manipulates and adds value to digital data. 'Voice telephony' will simply be a specialised software application running on the network (on the handset in fact), performing a specialised task - the conversion of speech into digital data and vice versa.

There will be many such network applications services, and not all of them will be person-to-person services. There are also networking functions to automate business functions or to support access to personal services. For example, a small business's cash registers will be connected directly to an accounting application running on a network server. This application will send 
weekly or monthly financial reports to the business. The data entered into an electronic organiser, with a wireless link to the network, could be stored by an application on a network server. These data could be re-displayed at a prearranged time or on demand if required. An entertainment application might respond to a user request by retrieving a digitised movie or soundtrack from a digital library and sending it to the user's TV or stereo set for performance.

An 'applications service provider' is therefore the provider of a service that is generated by an application running on the network.

The applications service function is clearly distinct from the infrastructure facilities provider function only where complete digitisation has been achieved and an applications-neutral platform has been established. To the extent that legacy analog technology and proprietary operating systems designed for specific applications are in place, there is blurring between the network facilities and the applications service functions. Increasingly, complete digitisation will allow the network facilities and application service functions to be clearly distinguished.

\section{User interfaces}

'User interfaces' is simply a reference to the fact that end-users will continue to employ a number of interfaces, and employ those interfaces in a number of different guises. The same person will be a two-way 'user' of a telephone handset and an 'audience' for a movie. There will never be an all-purpose interface because there will always be a range of applications services. What will vary will be the depth of user control over application or network configuration, and the user's degree of interaction with the process of service production and delivery.

This digital services value chain provides a robust framework for identifying likely issues and areas of potential market inefficiency and bottlenecks. Within this framework there will be tensions and changing balances of power and focus as between:

- content providers and connectivity providers;

- the centralisation of intelligence within network management systems versus the decentralisation of functions and control to 'information appliances' and control by users;

- business and consumer markets; and

- asymmetrical versus symmetrical network connections.

\section{Convergence in the Context of the Information Economy}

One of the primary reasons why convergence requires the greatest possible attention is its role in underpinning the whole information economy. Information 
and communications services have become the main drivers of economic and social futures and the main determinants of structural and business change.

Information processes and communications have the power to transform economic processes and the nature of wealth creation. As a result, the long term economic importance of the convergence industries is as intermediate inputs to the knowledge-based growth industries of the twenty-first century. These converging information industries are also important in their own right. The impact of convergence is thus not confined to the communications and content industries. The emergence of a new class of networked 'applications services', encompassing electronic commerce and other intelligent applications, is extending the reach and impact of convergence throughout the economy as a whole.

Finally, the impact of sector convergence is global. The growing trade exposure of, and international investment in, the sector means that Australia or any country market does not have the luxury of addressing convergence at its own pace. Each country market is in a contest for investment, and investment will flow to the countries where a friendly regulatory regime welcomes and promotes the organisational and technological innovation needed to realise the potential of digital services.

\section{Convergence and New Economic Markets}

As noted above, convergence is the progressive integration of the value chains of traditional communications and content industries within a single value chain based on the use of distributed digital technology. The process of convergence generates both demand and supply of new products and services that lead to the creation of new economic markets (convergence markets) for:

- networked application services, including content services;

- network services providing the connectivity for applications;

- networking facilities which create the infrastructure platforms; and goods and services used in conjunction with the above.

The definition of markets is where industry trends meet regulatory reality. Understanding the structure of new convergence markets enables us to identify and examine possible policy issues and the possible parameters for regulatory intervention. Particular strategies for regulatory intervention then need to be cast firmly within the context of industry realities. 


\section{Implications for Regulatory Policy}

There are several basic survival rules for efficacious policy adjustment within an environment of radical industry restructuring. Four, in particular are crucial to policy development in a period of radical change:

\section{Survival rule number 1: Synchronisation}

Policy-making must occur on timelines dictated by global industry restructuring, not by domestic political pressures. This will require prompt and energetic action based on a 'Pareto principle' for the allocation of effort, namely that priority should be given to key elements making up 80 per cent of the new policy framework that can be erected relatively easily. The remaining 20 per cent of issues cannot be allowed to derail the entire process.

\section{Survival rule number 2: Having a destination}

Regulation and re-regulation are not ends in themselves. The development of a new policy framework for the sector must be underpinned by clearly articulated national interest tests.

\section{Survival rule number 3: The right tool kit}

Service definitions must reflect convergence realities. Policies based on technology-specific definitions (notably cross media rules) are being undermined by technological change, growing service diversity, and growing commercial pressure for industry re-organisation.

Regulation is always directed towards industry interfaces where leverage can be gained over commercial behaviour. The identification of stable 'points of intervention' is essential to the implementation of policy intervention strategies. As technological change, market convergence and industry restructuring erode traditional points of intervention, so the effectiveness of intervention declines. Regulatory reform should begin by identifying new points of intervention which, whilst effective in addressing legitimate policy concerns, are robust against such changes. New industry definitions and new points for regulatory intervention will require innovative intervention strategies designed to achieve national interest objectives.

\section{Survival rule number 4: Keep moving}

Structural adjustment policies designed to accelerate and realise the benefits of industry restructuring are essential if country markets are to gain early mover advantage from sector restructuring. It would be a mistake to resist change or to 
regard convergence as a problem to be prevented. Instead, change needs to be promoted and challenged.

\section{The Way Forward}

With these issues in mind, a comprehensive review of the national regulatory framework for communications markets is clearly required. Piecemeal adjustments are, at best, stopgap measures and are costly to long-term development and efficiency. To be effective, the development of a convergence policy framework for the next decade should begin with a thorough, forwardlooking inquiry with extensive terms of reference encompassing the suggestions:

- Provide an assessment the economic and social costs and benefits of industry convergence.

- Set out desired scenarios for industry convergence outcomes.

- Develop policy objectives designed to achieve the desired outcomes.

- Identify areas where technological change is undermining existing service definitions and traditional points of regulatory intervention.

- Develop new market definitions and possible new points of regulatory intervention that are robust against rapid technological and commercial change.

- Identify market failures and industry 'bottlenecks' which may impede or prevent the realisation of desired outcomes.

- Provide recommendations for regulatory intervention strategies designed to address industry bottlenecks and market failures and achieve policy objectives, particularly the maintenance of media diversity.

- Provide recommendations for intervention strategies in regional areas, which address the structural and social differences between regional and metropolitan markets.

- Recommend changes to institutional structures and resourcing needed to address industry convergence.

- Recommend an orderly transitional regime, which minimises consumer penalties.

That the existing broadcasting and communications framework owes more to industry history than to a coherent set of communications policy objectives should be borne in mind when setting this new action agenda. A primary output of the review must be a set of coherent policy objectives for the communications sector. A soundly based approach to 'next generation' regulation of the communications sector will be forward-looking, and consistent with industry realities. Convergence should not continue to be regarded as a problem to be prevented. Rather, it should be recognised as an opportunity for substantial economic benefits for countries like Australia if they are prepared to formulate 
policies that positively encourage exploitation of new economies of scale and scope.

Service definitions must reflect convergence realities. Policies based on technology-specific definitions (especially in the area of cross media) are being overtaken by technological change and growing service diversity. This is a development to be welcomed, not feared. It will create new opportunities for value creation and diversity. Convergence regulation needs to be based on stable service definitions and stable 'points of intervention'. New definitions and new points of intervention will require new intervention strategies designed to achieve policy objectives.

The dichotomy between carriage and content is no longer relevant and intelligent applications services are the new and neglected element in the policy equation. Policies should be sufficiently flexible to address the real structural differences between metropolitan and regional markets. Intervention strategies must account for these differences. There is no justification for the blanket imposition of a 'vanilla' policy solution optimised for metropolitan markets.

The next generation agenda is certainly challenging, but Australia cannot afford to postpone addressing it.

\section{References}

Malaysia (1998), Laws of Malaysia, Communications and Multimedia Act 1998, Act 588.

OECD (1998), Cross-Ownership and Convergence: Policy Issues, Working Party on Telecommunications and Information Services Policies, Paris, November.

Squire, Sanders \& Dempsey LLP, with Analysis Ltd, (1998), Study On Adapting the EU Regulatory Framework to the Developing Multimedia Environment, Brussels, January.

This article is an updated version of a paper originally presented at the Communications Research Forum, Canberra, 24-25 September, 1998. 